\title{
Peso Vivo Final, Ganho de Peso, Características de Carcaça e Concentrações Plasmáticas de IGF-I e Hormônios Tireoideanos de Bezerros Mestiços Angus-Nelore Recebendo Somatotropina Bovina Recombinante (rbST) até a Desmama ${ }^{1}$
}

\author{
Rafael da Costa Cervieri², Mário De Beni Arrigoni ${ }^{3}$, Luis Arthur Loyola Chardulo ${ }^{4}$, Antônio \\ Carlos Silveira $^{5}$, Henrique Nunes de Oliveira ${ }^{6}$, Cyntia Ludovico Martins ${ }^{7}$
}

RESUMO - Objetivando estudar o efeito da somatotropina bovina recombinante (rbST) sobre o desempenho, as características de carcaça e as concentrações plasmáticas de IGF-I e hormônios tireoideanos, 36 bezerros mestiços $1 / 2$ Angus-Nelore com idade de $63 \pm 17$ dias e pesando $76,8 \pm 14,7 \mathrm{~kg}$, criados em pastagens de Brachiaria decumbens e suplementados em creep feeding, foram submetidos a dois tratamentos até a desmama (217 dias): I) 18 bezerros receberam 1,4 mg/kg de rbST (Boostin ${ }^{\circledR}$ ) a cada 14 dias; II) 18 bezerros controle receberam solução salina. As pesagens e colheitas de sangue foram realizadas a cada 28 dias e, à desmama, foram abatidos cinco animais de cada tratamento, para avaliação das características de carcaça. Os animais tratados apresentaram maior ganho de peso médio diário e peso vivo final, maiores concentrações plasmáticas de IGF-I e T4 que os bezerros controle. Os parâmetros peso de carcaça quente, rendimento de carcaça, pesos de traseiro e dianteiro, gordura peri-renal, peso de fígado, área de olho de lombo, espessura de gordura subcutânea, pesos dos músculos do quarto do traseiro e concentração plasmática de T3 não diferiram entre os tratamentos. A utilização de rbST proporcionou aumento de 7,9\% no ganho de peso vivo e alterou o perfil hormonal de bezerros suplementados em creep feeding durante a fase de cria, não refletindo, entretanto, em maior peso ou rendimento de carcaça.

Palavras-chave: creep feeding, crescimento, superprecoce

\section{Effects of Recombinant Bovine Somatotropin (rbST) on Production, Carcass Traits, and Plasmatic Concentrations of IGF-I and Thyroid Hormones on Pre-Weaning Crossbred Angus-Nellore Calves}

\begin{abstract}
The objective of this study was to evaluate the effects of recombinant bovine somatotropin (rbST) on production, carcass traits, and plasmatic concentrations of IGF-I and thyroid hormones on crossbred Angus-Nellore male calves. Thirty-six calves averaging $63 \pm 17$ days old and $76.8 \pm 14.7 \mathrm{~kg}$ of body weight (BW) grazing Brachiaria decumbens and creep fed were randomly assigned (18 calves per treatment) to one of two treatments until weaning (217 days) as follows: I) $1.4 \mathrm{mg}$ of $\mathrm{rbST}\left(\mathrm{Boostin}{ }^{\circledR}\right) / \mathrm{kg}$ of BW every 14 days or II) similar dosage of saline solution. Every 28 days calves were weighed and blood samples collected; at weaning, five animals from each treatment were slaughtered for carcass evaluation. The rbST-treated calves had greater average daily weight gain, final weight, and plasmatic concentrations of both IGF-I and T4 than those receiving saline solution. Weights of hot carcass, forequarter, hindquarter, hindquarter muscles, and liver as well as dressing percentage, kidney and pelvic fat, rib eye area, backfat thickness, and plasmatic concentrations of T3 were all not affected by rbST. Use of rbST increased body weight gain (7.9\%) and changed the hormonal status of pre-weaning creep-fed calves compared to the use of saline solution but did not improve carcass weight or dressing percentage.
\end{abstract}

Key Words: creep feeding, growth, calves

\section{Introdução}

O eixo somatotrófico, constituído principalmente pelo hormônio do crescimento $(\mathrm{GH})$, pelos fatores de crescimento semelhantes à insulina (IGF-I e IGF-II), pelas proteínas transportadoras e pelos receptores, exerce papel fundamental sobre o controle do metabolismo. Outros hormônios, como a insulina e os hormônios tireoideanos, estão diretamente envolvidos com o eixo somatotrófico, regulando a síntese e a disponibilidade de GH e IGF-I (Renaville et al., 2002).

Existe considerável interesse no desenvolvimento de métodos alternativos para estimular o crescimento dos animais domésticos de maneira segura e eficaz, sendo que o $\mathrm{GH}$, além de não oferecer riscos à saúde dos consumidores, tem propiciado ganhos significati-

\footnotetext{
1 Parte da tese do primeiro autor.

2 Professor do curso de Zootecnia da Universidade São Marcos, São Paulo-SP. Bolsista da Fapesp (cervieri@bigfoot.com).

3 Professor Doutor do Departamento de Melhoramento e Nutrição Animal, FMVZ/UNESP/Botucatu, SP, Brasil (arrigoni@fca.unesp.br)

4 Professor do Departamento de Química e Bioquímica, Instituto de Biociências, UNESP/Botucatu, SP, Brasil (lachard@ibb.unesp.br).

5 Professor Titular do Departamento de Melhoramento e Nutrição Animal, FMVZ/UNESP/Botucatu, SP, Brasil (acsilveira@fca.unesp.br).

6 Professor Doutor do Departamento de Melhoramento e Nutrição Animal, FMVZ/UNESP/Botucatu, SP, Brasil (hnunes@fca.unesp.br).

7 Pós-Doutoranda do Departamento de Melhoramento e Nutrição Animal/FMVZ/UNESP/Botucatu, SP, Brasil (cludovico@fca.unesp.br).
} 
vos na produtividade animal (Roche \& Quirke, 1992). Segundo McDowelL \& AnnisoN (1991), o GH promove o crescimento (estimula a divisão celular, o crescimento esquelético e a síntese protéica), é lipolítico (promove a liberação de ácidos graxos e inibe a síntese de gordura no tecido adiposo) e é diabetogênico (induz resistência periférica à insulina).

Mediante a administração de fontes exógenas de $\mathrm{GH}$ sob a forma de somatotropina bovina recombinante (rbST) em bovinos de corte em crescimento e terminação, têm-se observado aumento do desempenho, como maior ganho de peso e eficiência alimentar (Rausch et al., 2002), aumento da área do músculo Longissimus dorsi (Moseley et al., 1992), redução na quantidade de gordura subcutânea e intramuscular (Dalke et al., 1992), maior retenção de nitrogênio (Houseknecht et al., 1992) e aumento da concentração plasmática de IGF-I (Schwarz et al., 1993) e tiroxina (Holzer et al., 1999). Enright (1989), em revisão dos dados disponíveis para ruminantes, concluiu que a administração de rbST em bovinos confinados pode elevar a taxa de crescimento e a eficiência alimentar em 12 e $9 \%$, respectivamente, com concomitante efeito sobre a carcaça, aumentando a porção magra em $5 \%$ e reduzindo a de gordura em 15\%.

Entre os fatores que interferem no Sistema Superprecoce, o peso à desmama constitui-se em um dos mais importantes aspectos relacionados à sua eficiência biológica e econômica e a busca por práticas ou manejos que visem a obtenção de bezerros mais pesados deve ser considerada prioritária, com o objetivo de ampliar os limites produtivos do sistema. $\mathrm{O}$ adequado suprimento de nutrientes e a manipulação dos hormônios envolvidos no metabolismo, durante a fase de cria, podem interferir no crescimento animal de forma significativa durante este período.

Este estudo foi realizado com o objetivo de avaliar os efeitos da administração de rbST em bezerros mestiços Angus-Nelore suplementados em creep feeding até a desmama sobre o desempenho, as características de carcaça e as concentrações plasmáticas de IGF-I e dos hormônios tireoideanos (T3 e T4).

\section{Material e Métodos}

O experimento foi realizado na Fazenda Sant'Anna, localizada no município de Rancharia, SP, no período de novembro de 2000 a abril de 2001 . Foram utilizados 36 bezerros machos $1 / 2$ Angus- $1 / 2$ Nelore, oriundos de rebanho comercial, com idade de $63 \pm 17$ dias e pesando $76,8 \pm 14,7 \mathrm{~kg}$, filhos de mesmo touro da raça Aberdeen Angus. Os animais foram criados em mesma área (30 ha), em pastejo contínuo de Brachiaria decumbens e suplementados com ração concentrada no sistema creep feeding. A ração contendo $20 \%$ de PB e $72 \%$ de NDT (Tabela 1), formulada de acordo com as normas do NRC (1996), foi fornecida ad libitum diariamente em cochos cobertos, visando garantir suprimento adequado de energia metabolizável e proteína. As matrizes Nelore receberam apenas sal mineralizado durante o período experimental. Após identificação e controle sanitário (endo e ectoparasitos), os bezerros foram distribuídos em dois tratamentos: I) 18 bezerros receberam $1,4 \mathrm{mg} / \mathrm{kg}$ de rbST (Boostin ${ }^{\circledR}$ ) a cada 14 dias; II) 18 bezerros controle receberam solução salina na mesma dosagem. Tanto o rbST quanto a solução salina foram aplicados na região da base da cauda, em lados alternados, em injeção única

Tabela 1 - Composição do concentrado suplementar

Table 1 - Ingredient composition of the supplemental concentrate

\begin{tabular}{|c|c|}
\hline $\begin{array}{l}\text { Ingrediente } \\
\text { Ingredient }\end{array}$ & $\begin{array}{l}\% \text { da matéria seca } \\
\% \text { of dry matter }(\%)\end{array}$ \\
\hline Polpa cítrica & 42,2 \\
\hline Citrus pulp & \\
\hline $\begin{array}{l}\text { Farelo de mandioca } \\
\text { Cassava meal }\end{array}$ & 29,2 \\
\hline $\begin{array}{l}\text { Farelo de soja } \\
\text { Soybean meal }\end{array}$ & 13,4 \\
\hline Protenose & 11,9 \\
\hline $\begin{array}{l}\text { Corn gluten meal } \\
\text { Núcleo mineral* }\end{array}$ & 2,6 \\
\hline Minerals & \\
\hline $\begin{array}{l}\text { Uréia } \\
\text { Urea }\end{array}$ & 0,7 \\
\hline Rumensin & 0,02 \\
\hline
\end{tabular}

Composição química

Chemical composition

Matéria seca $\quad 88,0$

Dry matter

Proteína bruta

20,2

Crude protein

Extrato etéreo 2,9

Ether extract

Fibra em detergente neutro 22,0

Neutral detergent fiber

Cinzas

5,7

Ash

* Composição do sal mineral (por kg do produto) (Mineral composition/ kg): $180 \mathrm{~g} \mathrm{Ca}, 130 \mathrm{~g} \mathrm{P}, 1250 \mathrm{mg} \mathrm{Cu}, 5270 \mathrm{mg} \mathrm{Zn,} 2000 \mathrm{mg} \mathrm{Mn}$, $100 \mathrm{mg} \mathrm{Co}, 90 \mathrm{mg} \mathrm{I}, 15 \mathrm{mg} \mathrm{Se}, 2200 \mathrm{mg} \mathrm{Fe}, 1300 \mathrm{mg} \mathrm{F}$. 
por via subcutânea. Ao longo do período experimental, foram feitas amostragens periódicas do concentrado, para análise bromatológica de acordo com as normas da AOAC (1985).

Para monitoramento do peso vivo (PV) e do ganho de peso, foram realizadas pesagens em intervalos de 28 dias, sempre no período da manhã e no mesmo horário (8h).

Ao término da fase de cria (média de 217 dias de idade), cinco animais de cada tratamento foram abatidos no Frigorífico Frigol, localizado no município de Lençóis Paulista-SP, a $250 \mathrm{~km}$ do local onde foi realizado o experimento. Os animais foram transportados um dia antes do abate e permaneceram, em curral de concreto com acesso a água, sob jejum alimentar, durante 24 horas. No abate, após evisceração, foram pesados o fígado, a gordura perirenal e as meia-carcaças quentes. Em seguida, as meia-carcaças foram resfriadas em câmara fria $(0 \mathrm{a}$ $-2^{\circ} \mathrm{C}$ ) por 24 horas. $\mathrm{O}$ rendimento de carcaça quente foi calculado pela relação entre o peso da carcaça quente e o peso vivo final obtido na fazenda, expresso em porcentagem. Os pesos dos cortes traseiro e dianteiro foram obtidos após o resfriamento das carcaças por 24 horas. Durante a desossa, foram avaliados os pesos dos músculos do quarto traseiro: Semimembranosus, Gluteus medius, Quadriceps femoris, Semitendinosus, Psoas major e Biceps femoris. A espessura de gordura subcutânea, a área de olho de lombo, o comprimento e a profundidade da carcaça também foram avaliados após o resfriamento das carcaças, de acordo com metodologia descrita por Müller(1987).

As amostras de sangue foram colhidas a cada 28 dias, sempre pela manhã, por meio de venipunctura da jugular esquerda, na região do pescoço, em tubos contendo EDTA (BD Vacutainer Systems, Plymouth, Reino Unido), e imediatamente centrifugadas (6.000 rpm x $8 \mathrm{~min}$ ), para separação do plasma, que foi congelado em freezer a $-20^{\circ} \mathrm{C}$ até a realização das análises laboratoriais. A determinação do IGF-I foi realizada por ensaio radioimunométrico, segundo princípio descrito por Miles et al. (1974), utilizando-se o kit DSL-5600 ACTIVE IGF-I IRMA (DSL, Webster, Texas, EUA). O método é não-competitivo e inclui procedimento de extração, no qual o IGF-I é primeiramente separado de suas proteínas ligantes. Para a quantificação de $\mathrm{T} 3$ e $\mathrm{T} 4$, foi realizado radioimunoensaio, segundo os protocolos dos kits
GammaCoat $\mathrm{T}_{3}\left[{ }^{125} \mathrm{I}\right]$ RIA (DPC-Medlab, Los Angeles, CA, EUA) e GammaCoat $\left[{ }^{125} \mathrm{I}\right]$ Total $\mathrm{T}_{4}$ (DPC-Medlab, Los Angeles, CA, EUA), respectivamente. Ambos são métodos competitivos, realizados em tubos revestidos de anticorpos e, na determinação do T4, inicialmente é feita a separação do hormônio de suas proteínas ligantes. A leitura dos tubos marcados, nas análises de IGF-I, T3 e T4, foi realizada em contador gama (Gamma C-12, DPC Medlab, Los Angeles, CA, EUA) e os dados foram gerados em programa específico calibrado para cada hormônio.

O delineamento experimental utilizado foi o inteiramente casualizado. Os resultados foram analisados por meio do programa computacional Statistical Analysis System 6.12 (SAS, 1996) e os dados foram submetidos à análise de variância pelo procedimento GLM. Para o desempenho e as características de carcaça, as médias foram ajustadas pelo método dos quadrados mínimos e o peso vivo inicial foi incluído no modelo estatístico. As concentrações hormonais foram analisadas como medidas repetidas no tempo (Gill, 1986). O estabelecimento das correlações entre as concentrações de IGF-I e as variáveis de desempenho foi feito pelo procedimento CORR (SAS, 1996) e as médias foram comparadas a $5 \%$ de probabilidade.

\section{Resultados e Discussão}

Na Tabela 2 constam as médias ajustadas das variáveis de desempenho e características de carcaça. Os animais que receberam rbST apresentaram ganho de peso médio diário, ganho de peso total e peso vivo final maiores $(\mathrm{P}<0,05)$ que os animais controle. $\mathrm{O}$ ganho de PV diário foi 7,9\% maior nos bezerros tratados com rbST, o que está de acordo com os dados obtidos por Early et al. (1990a), que verificaram ganho de peso vivo $15 \%$ maior em bezerros castrados e confinados tratados com 20,6 mg/dia de rbST com aplicações diárias, e Holzer et al. (1999), que relataram ganhos de PV 9\% maiores para bezerros nãocastrados que receberam rbST (500 $\mathrm{mg}$ a cada 14 dias). Em experimento realizado com bezerros nãocastrados e confinados da raça Holandesa, recebendo $0,1 \mathrm{mg}$ de $\mathrm{bST} / \mathrm{kg}$ diariamente, Groenewegen et al. (1990) observaram maior ganho de PV diário (17,8\%) nos animais tratados. Moreira (2002), trabalhando com bezerros machos e fêmeas da raça Simbrasil suplementados em creep feeding, verificou maior ganho de PV $(10,7 \%)$ para as fêmeas tratadas com 
Tabela 2 - Médias ajustadas das variáveis de desempenho e características de carcaça Table 2 - Least square means of production and carcass traits

\begin{tabular}{|c|c|c|c|c|}
\hline \multirow[b]{2}{*}{$\begin{array}{l}\text { Parâmetro } \\
\text { Item }\end{array}$} & \multicolumn{2}{|c|}{$\begin{array}{l}\text { Tratamento } \\
\text { Treatment }\end{array}$} & \multirow[b]{2}{*}{$\mathrm{CV}(\%)$} & \multirow[b]{2}{*}{$\begin{array}{l}\text { Significância } \\
P \text {-value }\end{array}$} \\
\hline & $\begin{array}{l}\mathrm{rbST} \\
\mathrm{rbST}\end{array}$ & $\begin{array}{c}\text { Controle } \\
\text { Control } \\
\end{array}$ & & \\
\hline $\begin{array}{l}\text { Peso vivo inicial }{ }^{1} \\
\text { Initial body weight }^{2}\end{array}$ & 73,4 & 80,2 & 19,1 & $\mathrm{P}<0,05$ \\
\hline $\begin{array}{l}\text { Peso vivo final }{ }^{1} \\
\text { Final body weight }\end{array}$ & 247,6 & 234,9 & 5,3 & $\mathrm{P}<0,05$ \\
\hline $\begin{array}{l}\text { Ganho de peso médio diário }{ }^{1} \\
\text { Average daily gain }\end{array}$ & 1,101 & 1,020 & 7,5 & $\mathrm{P}<0,05$ \\
\hline $\begin{array}{l}\text { Ganho de peso total }{ }^{1} \\
\text { Total weight gain }\end{array}$ & 170,8 & 158,1 & 7,5 & $\mathrm{P}<0,05$ \\
\hline $\begin{array}{l}\text { Peso de carcaça quente } \\
\text { Hot carcass weight }\end{array}$ & 125,2 & 125,5 & 4,7 & NS \\
\hline $\begin{array}{l}\text { Rendimento de carcaça }{ }^{2} \\
\text { Dressing } \%\end{array}$ & 50,9 & 51,7 & 2,6 & NS \\
\hline $\begin{array}{l}\text { Gordura peri-renal }^{2} \\
\text { Kidney and pelvic fat }\end{array}$ & 1,4 & 1,7 & 22,9 & NS \\
\hline $\begin{array}{l}\text { Comprimento } \\
\text { Length }\end{array}$ & 115,2 & 115,8 & 2,3 & NS \\
\hline $\begin{array}{l}\text { Profundidade }{ }^{2} \\
\text { Depth }\end{array}$ & 30,5 & 30,1 & 5,3 & NS \\
\hline $\begin{array}{l}\text { Área de olho de lombo }{ }^{2} \\
\text { Rib eye area }\end{array}$ & 55,5 & 55,3 & 10,6 & NS \\
\hline $\begin{array}{l}\text { Espessura de gordura subcutânea }{ }^{2} \\
\text { Backfat thickness }\end{array}$ & 0,7 & 1,2 & 96,3 & NS \\
\hline $\begin{array}{l}\text { Peso do fígado } \\
\text { Liver weight }\end{array}$ & 2,9 & 3,2 & 10,7 & NS \\
\hline
\end{tabular}

NS - não-significativo (NS - not significant). ${ }^{1} \mathrm{n}=18 ;{ }^{2} \mathrm{n}=5$.

rbST $(0,15 \mathrm{mg} / \mathrm{kg} /$ dia a cada 14 dias $)$, não havendo diferença para os machos. Em ensaios realizados com novilhos em terminação confinados, Wagner et al. (1988), Moseley et al. (1992), Rumsey et al. (1996) e Rausch et al. (2002) verificaram aumento médio de $9 \%$ no ganho de PV diário em animais tratados com rbST.

Vann et al. (1998) não observaram diferenças significativas quanto ao ganho de PV médio diário entre os bezerros tratados com rbST $(0,09 \mathrm{mg} / \mathrm{kg} / \mathrm{dia}$ a cada 14 dias) e o grupo controle durante a fase de cria com suplementação em creep feeding, enquanto Maltin et al. (1990), trabalhando com bezerros Holandês lactentes, não verificaram diferenças no ganho de $\mathrm{PV}$ entre os animais suplementados diariamente com extrato de pituitária $(3,5 \mathrm{mg}$ de $\mathrm{bST})$ e as do grupo controle. A baixa dosagem utilizada por Maltin et al. (1990) pode ter contribuído para a ausência de resposta sobre o desempenho. Chardulo (1996) não encontrou diferença significativa para ganho de PV diário e final em bezerros tratados com rbST (250 mg a cada 14 dias) e confinados após a desmama, enquanto 
Morais (1999), fornecendo $500 \mathrm{mg}$ de rbST a cada 28 dias, a bezerros confinados oriundos de diferentes cruzamentos com o Nelore, também não encontrou diferença significativa para PV final e ganho diário. As diferenças encontradas nas respostas do ganho de PV diário e final podem ser atribuídas ao regime alimentar (confinamento vs creep feeding), à dosagem e à freqüência de aplicação (diário vs a cada 14 ou 28 dias), ao sexo e à idade, variáveis consideradas por Enright (1989) como importantes sobre os efeitos fisiológicos e produtivos atribuídos à somatotropina.

$O$ peso de carcaça quente, o rendimento de carcaça, o peso de gordura peri-renal, o comprimento e profundidade da carcaça, a área de olho de lombo, a espessura de gordura subcutânea e o peso do fígado não diferiram entre os tratamentos $(\mathrm{P}>0,05)$. Confirmando estes resultados, Groenewegen et al. (1990), Enright et al. (1990), Dalke et al. (1992), Chardulo (1996) e Morais (1999) não constataram efeito da rbST sobre o peso de carcaça de bezerros e novilhos confinados. Porém, Vestergaard et al. (1995), Rumsey et al. (1996) e Vann et al. (1998) verificaram aumento médio do peso de carcaça de 7,6\% em bezerros e novilhos tratados com rbST.

O maior ganho de PV observado nos bezerros que receberam rbST não refletiu em ganhos adicionais ou em maior rendimento de carcaça, inclusive podendo notar-se redução numérica do rendimento $(-1,6 \%)$ nos animais tratados. Resultados semelhantes foram relatados por Groenewegen et al. (1990) e Holzer et al. (2000) em bezerros, e por Enright et al. (1990) e Dalke et al. (1992), em novilhos confinados, que encontraram rendimentos de carcaça menores nos animais tratados com rbST. Early et al. (1990a) concluíram que o ganho de PV adicional obtido em bezerros confinados suplementados com rbST decorreu do acréscimo de peso em componentes não carcaça e conteúdo gastrintestinal, uma vez que não houve diferença no peso de carcaça e o rendimento foi menor nos animais suplementados, o que também foi observado por Wagner et al. (1988) e Holzer et al. (1999). Esta conclusão foi confirmada em trabalhos subseqüentes, nos quais os pesos e as taxas de ganho diário de fígado, rins, pulmões, traquéia e cabeça foram maiores nos novilhos tratados com rbST (Early et al., 1990b), assim como as taxas de deposição de proteína no fígado, nos rins, no estômago, no couro e na cabeça, não havendo diferença quanto à taxa de deposição protéica na carcaça (Early et al., 1990c).
Rumsey et al. (1996), ao fornecerem rbST na dosagem de $0,1 \mathrm{mg} / \mathrm{kg} / \mathrm{dia}$ (Somavubove ${ }^{\circledR}$ ) a novilhos confinados, observaram aumento do peso de carcaça $(1,3 \%)$, mas com concomitante acréscimo de componentes não-carcaça, principalmente fígado, coração, rins, couro e sangue, sendo que o rendimento de carcaça não diferiu em relação aos animais não suplementados. Apesar de haver redução da deposição de gordura na carcaça de animais tratados com rbST, a qual contribui para diminuição do rendimento de carcaça, o aumento das taxas de deposição e do peso dos componentes não pertencentes à carcaça parecem ser responsáveis pela ausência de efeito do GH sobre a relação $\mathrm{PV} /$ peso de carcaça.

A avaliação do comprimento e da profundidade da carcaça pode ser considerada indicativo do desenvolvimento ósseo (Müller, 1987), não se observando neste trabalho diferença entre os tratamentos para as duas variáveis (Tabela 2). Vann et al. (1998) e Moreira (2002) não encontraram efeito da somatotropina sobre o comprimento do fêmur e o peso de ossos e sobre o perímetro de canela, respectivamente, assim como Early et al. (1990b) e Schwarz et al. (1993) não observaram efeito da aplicação de rbST sobre o peso total de ossos e sobre a relação músculo/ ossos da carcaça. Possivelmente o tratamento com rbST tenha maior potencial de atuação sobre as fibras colágenas e o tecido conectivo que sobre a massa óssea especificamente (Vann et al., 1998).

Mediante a administração de rbST, tem-se observado aumento da área de olho de lombo (AOL) em novilhos (Elsasser et al., 1989). Vann et al. (1998) encontraram maior AOL para os bezerros tratados com rbST durante a fase de cria, assim como Vestergaard et al. (1995), para bezerras da raça Holandesa pré-púberes. Entretanto, como nesta pesquisa, Dalke et al. (1992) observaram que novilhos mestiços confinados recebendo doses crescentes de $\operatorname{rbST}(0,40,80$ ou $160 \mathrm{mg} / \mathrm{semana})$ não apresentaram aumento da AOL em nenhuma das dosagens testadas, do mesmo modo que Rausch et al. (2002), trabalhando com novilhos confinados, e Moreira (2002), com bezerros e bezerras suplementados em creep feeding, não verificaram efeito da somatotropina sobre a AOL em avaliação feita por ultra-sonografia.

Um dos efeitos mais discutidos da somatotropina está relacionada à redução do teor ou da quantidade de gordura na carcaça. Muitos autores têm relatado redução do teor de gordura (Groenewegen et al., 
1990; Dalke et al., 1992; Schwarz et al., 1993; Holzer et al., 1999), diminuição na espessura de gordura subcutânea (Peters, 1986; Early et al., 1990a; Dalke et al., 1992) e menor deposição de gorduras pélvica e renal (Holzer et al., 1999; Holzer et al., 2000) na carcaça de animais tratados com rbST. Em contraste com estas observações neste estudo e naqueles realizados por Tripp et al. (1998) e Rausch et al. (2002), com medidas avaliadas por ultra-sonografia, não houve efeito da somatotropina sobre a espessura de gordura subcutânea, a qual, segundo Vann et al. (1998), que também abateram bezerros à desmama e não constataram efeito da rbST sobre a espessura de gordura e porcentagem de gordura renal, pélvica e cardíaca, não é uma medida representativa, uma vez que a mensuração é realizada em uma idade em que a espessura de gordura é mínima.

Os bezerros controle e os tratados com rbST apresentaram pesos de fígado semelhantes (Tabela 2). Da mesma forma, Groenewegen et al. (1990) e Vann et al. (1998) relataram resultados semelhantes em bezerros, nos quais o fornecimento de rbST não afetou os pesos de fígado, coração e rins. Em contraste, Early et al. (1990b), Moseley et al. (1992), Schwarz et al. (1993) e Rumsey et al. (1996) reportaram aumento no peso de fígado em novilhos e novilhas confinados que receberam rbST.
Quanto aos pesos dos quartos dianteiro e traseiro e dos músculos do quarto traseiro, não foi observada diferença $(\mathrm{P}>0,05)$ entre os tratamentos em nenhuma das variáveis estudadas (Tabela 3). Early et al. (1990a), Chardulo (1996) e Morais (1999) também não observaram diferenças no peso dos quartos traseiro e dianteiro de bezerros confinados tratados com rbST, como também foi verificado por Holzer et al. (2000). Entretanto, redução do rendimento de dianteiro e maiores rendimentos de traseiro (Holzer et al., 1999) e de tecido muscular na carcaça (Vann et al., 1998) foram observados em bezerros suplementados com rbST.

$\mathrm{O}$ estímulo do $\mathrm{GH}$ à síntese protéica parece ser músculo dependente, não havendo efeito uniforme em todos os grupos musculares. Eisemann et al. (1989) sugeriram que o incremento da taxa fracional de síntese protéica propiciado pelo GH depende do músculo estudado. Elsasser et al. (1998) observaram, em novilhos confinados, aumento de peso e maior taxa de deposição protéica nos músculos Rectus femoris e Tríceps brachii mediante o fornecimento de rbST (0,1 mg/kg/dia), sendo que o Supraspinatus, Psoas major e Semitendinosus não apresentaram alteração de peso ou mudança na taxa de deposição protéica em relação ao grupo controle. Groenewegen et al. (1990),

Tabela 3 - Médias ajustadas dos pesos dos quartos dianteiro e traseiro e dos músculos do quarto traseiro Table 3 - Hindquarter, forequarter, and hindquarter muscles weights

\begin{tabular}{|c|c|c|c|c|}
\hline \multirow[b]{2}{*}{$\begin{array}{l}\text { Parâmetro } \\
\text { Item }\end{array}$} & \multicolumn{2}{|c|}{$\begin{array}{c}\text { Tratamento } \\
\text { Treatment }\end{array}$} & \multirow[b]{2}{*}{$\mathrm{CV}(\%)$} & \multirow[b]{2}{*}{$\begin{array}{c}\text { Significância } \\
P \text {-value }\end{array}$} \\
\hline & $\begin{array}{l}\mathrm{rbST} \\
\mathrm{rbST}\end{array}$ & $\begin{array}{c}\text { Controle } \\
\text { Control }\end{array}$ & & \\
\hline $\begin{array}{l}\text { Dianteiro } \\
\text { Forequarter }\end{array}$ & 24,2 & 24,4 & 5,7 & NS \\
\hline $\begin{array}{l}\text { Traseiro } \\
\text { Hindquarter }\end{array}$ & 31,0 & 30,5 & 4,3 & NS \\
\hline Semimembranosus (Coxão mole) & 4,1 & 4,4 & 5,2 & NS \\
\hline Gluteus medius (Alcatra) & 1,7 & 1,6 & 8,0 & NS \\
\hline Quadriceps femoris (Patinho) & 2,6 & 2,4 & 7,1 & NS \\
\hline Semitendinosus (Lagarto) & 1,1 & 1,2 & 5,6 & NS \\
\hline Psoas major (Filé mignon) & 0,90 & 0,88 & 5,6 & NS \\
\hline Biceps femoris (Picanha + Coxão duro) & 2,5 & 2,3 & 9,1 & NS \\
\hline
\end{tabular}

NS - não significativo (NS - not significant); ${ }^{*} \mathrm{n}=5$. 
em bezerros Holandês abatidos aos três meses de idade e Early et al. (1990b), avaliando as carcaças de novilhos confinados, não encontraram efeito da administração de rbST sobre o peso dos músculos Biceps femoris, Semitendinosus e Semimembranosus.

Na Tabela 4 são apresentadas as médias das concentrações plasmáticas de IGF-I, T3 e T4. Os animais suplementados com rbST apresentaram concentrações de IGF-I e T4 maiores que os animais controle $(\mathrm{P}<0,05)$, não havendo diferença para $\mathrm{T} 3$. Resultados semelhantes quanto ao IGF-I foram obtidos por Holzer et al. (2000), que observaram aumento dos níveis séricos de IGF-I em bezerros holandes confinados recebendo rbST, enquanto Moreira (2002) constatou maior concentração de IGF-I em fêmeas Simbrasil tratadas com rbST durante a fase de cria. Entretanto, Vann et al. (1998) e Holzer et al. (1999) não verificaram efeito do tratamento com rbST sobre a concentração sérica de IGF-I em bezerros.

$\mathrm{O}$ aumento da concentração plasmática de IGF-I verificado nos animais que receberam rbST $(34,1 \%$ em relação ao controle) corrobora a informação de que a administração exógena de somatotropina resulta em elevação dos níveis plasmáticos (Vernon, 1989), como também constatado por Sandles \& Peel (1987), em novilhas; Dalke et al. (1992) e Tripp et al. (1998), em novilhos confinados; Vestergaard et al. (1995), em bezerras; e McLaughlin et al. (1993), em ovinos. Os principais efeitos estimulatórios de crescimento do GH são mediados pelas somatomedinas, principalmente IGF-I, sintetizado no fígado e em outros órgãos, podendo atuar tanto no próprio órgão em que foi sintetizado (ação autócrina) ou mesmo em diferentes tecidos (ação parácrina) (Coutinho, 1996).
Quanto aos hormônios tireoideanos, verificou-se que os níveis de T3 não diferiram entre os tratamentos e que a concentração média de $\mathrm{T} 4$ foi $15,6 \%$ superior nos bezerros suplementados com $\operatorname{rbST}(\mathrm{P}<0,05)$. Da mesma forma, Holzer et al. (1999) obtiveram aumento da concentração de T4 nos bezerros suplementados com rbST e ausência de efeito para T3. Por outro lado, as concentrações de T4 avaliadas por Moreira (2002) foram maiores nos bezerros não tratados com rbST, não havendo diferença quanto ao T3, enquanto Eisemann et al. (1986) e Holzer et al. (2000) não constataram efeito da somatotropina nos níveis de T3 e T4 em novilhas e bezerros confinados. As inter-relações entre o eixo somatotrófico e os hormônios tireoideanos são fartamente relatadas. Os hormônios tireodeanos atuam no controle da produção de receptores das somatomedinas, influenciam a síntese e a secreção de GH pela pituitária, regulam a ação do GH sobre as epífises ósseas e também controlam a expressão do mRNA de IGF-I (Roche \& Quirke, 1992). Gerrits et al. (1998) destacam que o hormônio T3 exerce importante ação sobre a produção e liberação de IGF-I e Elsasser et al. (1993) concluíram que, em novilhos, elevados níveis séricos de T3 reduzem a resposta do IGF-I à administração da somatotropina, com conseqüente redução da taxa de deposição de proteína nos tecidos.

Nas Figuras 1, 2 e 3 são apresentadas as concentrações plasmáticas dos hormônios durante o período experimental de 154 dias, sendo possível observar grande variação nas concentrações plasmáticas de T3 e T4; para o T4 (Figura 2), houve diferença a favor do controle no período 3 e os bezerros suplementados apresentaram maior concentração nos períodos 1, 2 e $6(\mathrm{P}<0,05)$. Segundo Trenkle (1978), os hormônios

Tabela 4 - Médias das concentrações plasmáticas de IGF-I, T3 e T4

Table 4 - Mean plasmatic concentrations of IGF-I, T3 and T4

\begin{tabular}{|c|c|c|c|c|}
\hline \multirow[b]{2}{*}{$\begin{array}{l}\text { Parâmetro } \\
\text { Item }\end{array}$} & \multicolumn{2}{|c|}{$\begin{array}{c}\text { Tratamento } \\
\text { Treatment }\end{array}$} & \multirow[b]{2}{*}{$\mathrm{CV}(\%)$} & \multirow[b]{2}{*}{$\begin{array}{c}\text { Significância } \\
P \text {-value }\end{array}$} \\
\hline & $\begin{array}{l}\mathrm{rbST} \\
\mathrm{rbST} \\
\end{array}$ & $\begin{array}{c}\text { Controle } \\
\text { Control }\end{array}$ & & \\
\hline & & & & \\
\hline IGF-I & 213,60 & 159,28 & 48,1 & $\mathrm{P}<0,05$ \\
\hline $\mathrm{T} 4$ & 8,59 & 7,43 & 47,1 & $\mathrm{P}<0,05$ \\
\hline
\end{tabular}

NS - não-significativo (NS- not significant); ${ }^{*} \mathrm{n}=18$. 


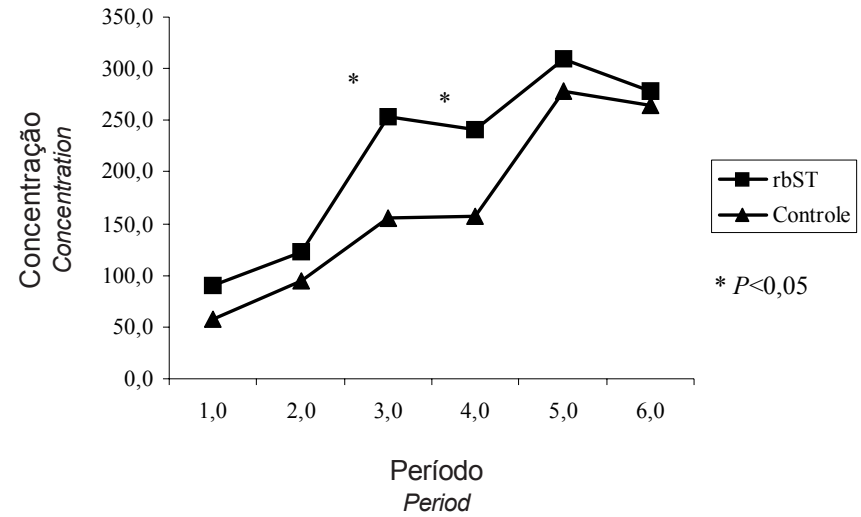

Figura 1 - Concentrações plasmáticas de IGF-I (ng/mL) entre 63 e 217 dias de idade.

Figure 1 - Plasmatic concentrations of IGF-I ( $\mathrm{g} / \mathrm{mL}$ ) between 63 and 217 days of age.

tireoideanos são sensíveis às alterações de temperatura ambiente, ao manejo ou estresse e ao status nutricional, fatores que podem ter contribuído para a grande variação ocorrida entre os períodos. Independentemente do tratamento, o comportamento apresentado pela triiodotironina foi, com exceção do período 3 , semelhante àquele observado para a tiroxina (Figura 3), com aumentos e reduções das concentrações nos mesmos períodos, evidenciando a forte relação entre os dois hormônios. O T4 é o principal produto secretado pela glândula tireóide e o T3 corresponde à forma biologicamente ativa. A conversão de T4 em T3 no fígado e nos rins constitui-se em importante fonte de T3 (Kahl et al., 1984).

Quanto ao IGF-I (Figura 1), observa-se aumento da concentração ao longo dos períodos avaliados, com os bezerros que receberam rbST apresentando níveis plasmáticos de IGF-I mais elevados que os bezerros controle nos períodos 3 e $4(\mathrm{P}<0,05)$. Govoni et al. (2004) verificaram aumento nos níveis plasmáticos de IGF-I em bezerros Hereford tratados com rbST no período de 50 a 350 dias de idade. Independentemente do tratamento, o comportamento apresentado confirma que as concentrações de IGF-I são em idade dependentes, ocorrendo aumento dos níveis plasmáticos com o avançar da idade, principalmente na puberdade (Renaville et al., 1993; Pagano et al., 2001).

O IGF-I é considerado importante mediador da ação metabólica e de estímulo ao crescimento propiciado pela somatotropina, correlacionando-se positivamente à taxa de ganho de PV e à eficiência alimentar, sendo definido por Stick et al. (1998) como eficiente preditor fisiológico do crescimento. Neste sentido,

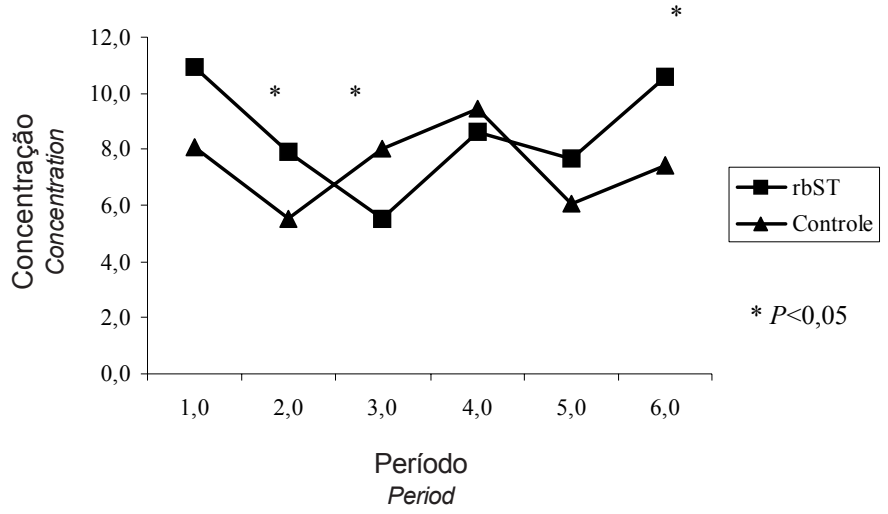

Figura 2 - Concentrações plasmáticas de T4 ( $\mu \mathrm{g} / \mathrm{dL})$ entre 63 e 217 dias de idade.

Figure 2 - Plasmatic concentrations of T4 $(\mu \mathrm{g} / \mathrm{dL})$ between 63 and 217 days of age.

Weeks (1996) relatou que, em ovinos selecionados para maior peso à desmama, os níveis plasmáticos de IGF-I foram mais elevados, enquanto Breier \& Saverwein (1995) verificaram que a seleção de linhagens de camundongos e ovinos, com base na magnitude da concentração plasmática de IGF-I, resultou em diferenças marcantes nas taxas de crescimento. Davis \& Simmen (2000) concluíram que o IGF-I pode vir a ser um critério de seleção útil para a melhoria da marmorização e da qualidade da carcaça. Associando as concentrações de IGF-I observadas neste estudo aos resultados de PV final e ganho de peso, obtêm-se coeficientes de correlação em torno de $0,33(\mathrm{P}<0,10)$ para o ganho de peso e de $0,36(\mathrm{P}<0,10)$ para $\mathrm{PV}$ final, evidenciando a relação positiva entre crescimento e nível plasmático de IGF-I, constatado pelo maior ganho e PV final obtidos nos animais suplementados com rbST, os quais também apresentaram maior concentração plasmática de IGF-I. Groenewegen et al. (1990), apesar de não terem encontrado efeito da aplicação de rbST sobre a concentração plasmática de IGF-I, obtiveram alta correlação entre a concentração plasmática de IGF-I e o ganho de peso diário, de modo que a análise de regressão resultou em alta relação linear entre os parâmetros. Stick et al. (1998), ao analisarem as concentrações plasmáticas de IGF-I de novilhos cruzados após a desmama, submetidos a diferentes ofertas de matéria seca $(80,90$ e $100 \%$ do ad libitum), e sua relação com o ganho de peso e a eficiência alimentar, relataram correlações positivas entre IGF-I e os dois parâmetros de desempenho, sendo que a análise de regressão indicou que cada $1 \mathrm{ng} / \mathrm{mL}$ de aumento na concentração de IGF-I sérico correspondia a au- 


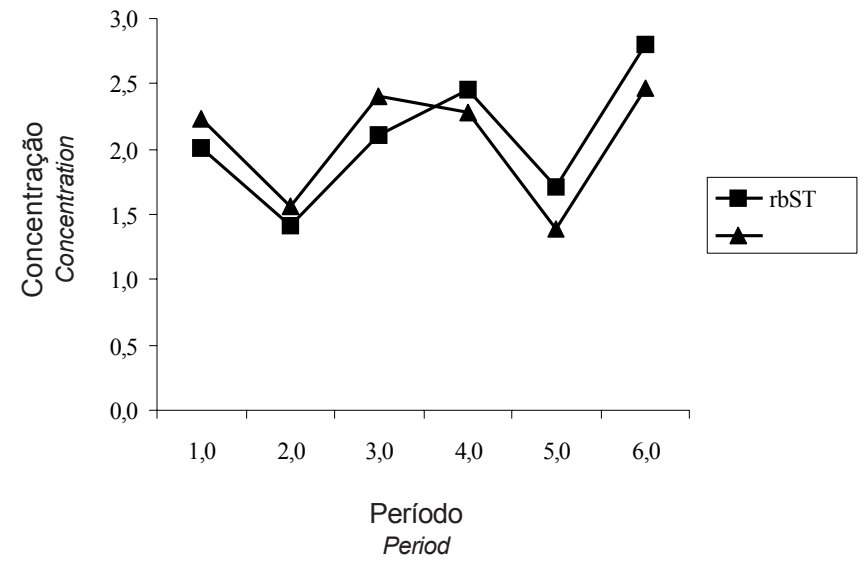

Figura 3 - Concentrações plasmáticas de T3 (ng/mL) entre 63 e 217 dias de idade.

Figure 3 - Plasmatic concentrations of $T 3(\mathrm{ng} / \mathrm{mL})$ between 63 and 217 days of age.

mento de $0,00135 \mathrm{~kg} /$ dia no ganho de peso médio diário e a um incremento da eficiência alimentar de $0,0001 \mathrm{~kg}$ de ganho/kg de MS ingerido. Os autores concluíram que o uso de IGF-I pode ser considerado um procedimento auxiliar de seleção para crescimento e eficiência alimentar.

A somatotropina exerce papel fundamental sobre o controle homeorrético da partição de nutrientes e o sistema GH/IGF-I atua decisivamente sobre o desempenho e metabolismo em diversas condições fisiológicas (Bauman, 1999). Neste estudo, os efeitos da somatotropina sobre o crescimento e metabolismo refletiram-se em maior taxa de ganho de peso, com conseqüente aumento do peso à desmama, e nas concentrações plasmáticas de IGF-I mais elevadas obtidas nos bezerros tratados, as quais correlacionouse positivamente com as variáveis de desempenho avaliadas. Porém, não houve efeito estimulatório da rbST sobre características importantes, como peso e rendimento de carcaça, área de olho de lombo e peso de grupos musculares de maior valor econômico, bem como na deposição de gordura subcutânea, sendo que respostas semelhantes foram relatadas com certa freqüência em trabalhos anteriores realizados tanto com bezerros em crescimento quando com novilhos em terminação. Desta forma, talvez a partição de nutrientes atribuída ao GH se dê em favor de tecidos e órgãos de menor valor, o que, no caso de bezerros desmamados, não se caracteriza como um comportamento desfavorável, uma vez que estes animais são comercializados com base no peso vivo.

\section{Conclusões}

A utilização da somatotropina bovina recombinante aumentou o peso vivo mas não refletiu em maior peso ou em rendimento de carcaça de bezerros suplementados em creep feeding até a desmama.

$\mathrm{O}$ fornecimento de somatotropina exógena alterou as concentrações plasmáticas de T4 e principalmente de IGF-I de bezerros durante a fase de cria.

Quanto à viabilidade econômica, o ganho de peso vivo adicional propiciado pela somatotropina não se traduziu em retorno financeiro, pois a despesa com a aplicação do hormônio foi substancialmente maior que a receita proveniente do maior peso à desmama.

\section{Agradecimento}

Á FAPESP (Fundação de Amparo à Pesquisa do Estado de São Paulo), pela bolsa de estudos concedida.

\section{Literatura Citada}

ASSOCIATION OF OFFICIAL ANALYTICAL CHEMISTS AOAC. Official methods of analysis. 13.ed. Washington, D.C.: 1985. 1094p.

BAUMAN, D.E. Bovine somatotropin and lactation: from basic science to commercial application. Domestic Animal Endocrinology, v.17, p.101-116, 1999.

BREIER, B.H.; SAVERWEIN, H. Regulation of growth in ruminants by the somatotropic axis. In: INTERNATIONAL SYMPOSIUM ON RUMINANT PHYSIOLOGY, 8., 1995, Stuttgart. Proceedings... Stuttgart: 1995. p.451-484.

CHARDULO, L.A.L. Efeito da somatotropina bovina recombinante (rbST) no Desempenho e características químicas da carne de bovinos jovens Nelore e mestiços Simental x Nelore. Botucatu: Universidade Estadual Paulista, 1996. 37p. Dissertação (Mestrado em Produção e Nutrição Animal) - Universidade Estadual Paulista, 1996.

COUTINHO, L.L. Promotores de crescimento. In: PRODUÇÃO DE NOVILHOS PRECOCES, 1996, Piracicaba. SIMPÓSIO SOBRE PRODUÇÃO ANIMAL, 6., 1996, Piracicaba. Anais... Piracicaba: Fundação de Estudos Agrários Luiz de Queiroz, 1996. p.229-246.

DALKE, B.S.; ROEDER, R.A.; KASER, T.R. et al. Doseresponse effects of recombinant bovine somatotropin implants on feedlot performance in steers. Journal of Animal Science, v.70, p.2130-2137, 1992.

DAVIS, M.E.; SIMMEN, R.C. Genetic parameter estimates for serum insulin-like growth factor-I concentration and carcass traits in Angus beef cattle. Journal of Animal Science, v.78, p.2305-2313, 2000.

EARLY, R.J.; McBRIDE, B.W.; BALL, R.O. Growth and metabolism in somatotropin-treated steers: I. Growth, serum chemistry and carcass weights. Journal of Animal Science, v.68, p.4134-4143, 1990a. 
EARLY, R.J.; McBRIDE, B.W.; BALL, R.O. Growth and metabolism in somatotropin-treated steers: II. Carcass and non carcass tissue components and chemical composition. Journal of Animal Science, v.68, p.4144-4152, 1990b.

EARLY, R.J.; McBRIDE, B.W.; BALL, R.O. Growth and metabolism in somatotropin-treated steers: III. Protein synthesis and tissue energy expenditures. Journal of Animal Science, v.68, p.4153-4166, 1990c.

EISEMANN, J.H.; HAMMOND, A.C.; BAUMAN, D.E. et al. Effect of bovine growth hormone administration on metabolism of growing hereford heifers: protein and lipid metabolism and plasma concentrations of metabolites and hormones. Journal of Nutrition, v.116, p.2504-2515, 1986.

EISEMANN, J.H.; HAMMOND, A.C.; RUMSEY, T.S. Tissue protein synthesis and nucleic acid concentrations in steers treated with somatotropin. British Journal of Nutrition, v.62, p.657-671, 1989 .

ELSASSER, T.H.; RUMSEY, T.S.; HAMMOND, A.C. Influence of diet on basal and growth hormone-stimulated plasma concentrations of IGF-I in beef cattle. Journal of Animal Science, v.67, p.128-137, 1989.

ELSASSER, T.H.; RUMSEY, T.S.; KAHL, S. Relationships between the thyroid and somatotropic axes in steers: II. Effects of thyroid status on plasma concentrations of insulin- like growth factor I (IGF-1) and the IGF-1 response to growth hormone. Domestic Animal Endocrinology, v.10, p.71-81, 1993.

ELSASSER, T.H.; RUMSEY, T.S.; KAHL, S.M. et al. Effects of Synovex-S and recombinant bovine growth hormone (Somavubove) on growth responses of steers: III. Muscle growth and protein responses. Journal of Animal Science, v.76, p.2346-2353, 1998.

ENRIGHT, W.J. Effects of administration of somatotropin on growth, feed efficiency and carcass composition of ruminants: a review. In: SEJRSEN, K.; VESTERGAARD, M.; NEIMANNSORENSEN, A. (Eds.) Use of somatotropin on livestock production. London: Elsevier, 1989. p.132-156.

ENRIGHT, W.J.; QUIRKE, J.F.; GLUCKMAN, P.D. et al. Effects of long term administration of pituitary-derived bovine growth hormone and estradiol on growth in steers. Journal of Animal Science, v.68, p.2345-2356, 1990.

GERRITS, W.J.J.; DECUYPERE, E.; VERSTEGEN, M.W.A. et al. Effect of protein and protein-free energy intake on plasma concentrations of insulin-like growth factor I and thyroid hormones in preruminant calves. Journal of Animal Science, v.76, p.1356-1363, 1998.

GILL, J.L. Repeated measurement: sensitive tests for experiments with few animals. Journal of Animal Science, v.63, p.943-950, 1986.

GOVONI, K.E.; HOAGLAND, T. A.; ZINN, S.A. The ontogeny of the somatotropic axis in Hereford calves from birth to one year of age and its response to administration of exogenous bovine somatotropin. Journal of Animal Science, v.82, p.1646-1645, 2004

GROENEWEGEN, P.P.; McBRIDE, B.W.; BURTON, J.H. et al. Effect of bovine somatotropin on the growth rate, hormone profiles and carcass composition of Holstein bull calves. Domestic Animal Endocrinology, v.7, p.43-54, 1990

HOLZER, Z.; AHARONI, Y.; BROSH, A. et al. The effects of long-term administration of recombinant bovine somatotropin (Posilac) and Synovex on performance, plasma hormone and amino acid concentration, and muscle and subcutaneous fat fatty acid composition in Holstein-
Friesian bull calves. Journal of Animal Science, v.77, p.1422-1430, 1999.

HOLZER, Z.; AHARONI, Y.; BROS, A. et al. The influence of recombinant bovine somatotropin on dietary energy levelrelated growth of Holstein-Friesian bull calves. Journal of Animal Science, v.78, p.621-628, 2000.

HOUSEKNECHT, K.L.; BAUMAN, D.E.; FOX, D.G. et al. Abomasal infusion of casein enhances nitrogen retention in somatotropin-treated steers. Journal of Nutrition, v.122, p.1717-1725, 1992.

KAHL, S.; BITMAN, J.; RUMSEY, T.S. Extra-thyroidal thyroxine-5'-monodeiodinase activity in cattle. Domestic Animal Endocrinology, v.1, p.279-290, 1984.

MALTIN, C.A.; DELDAY, S.M.; INNES, G.M. et al. Effects of bovine pituitary growth hormone alone or in combination with the b-agonist clenbuterol on muscle growth and composition in veal calves. British Journal of Nutrition, v.63, p.35-545, 1990.

McDOWELL, G.H.; ANNISON, E.F. Hormonal control of energy and protein metabolism. In: INTERNATIONAL SYMPOSIUM ON RUMINANT PHYSIOLOGY, 7., 1991, London. Proceedings...London: Academic Press, 1991. p.231-253.

McLAUGHLIN, C.L.; HEDRICK, H.B.; VEENHUIZEN, J.J. et al. Comparison of performance, clinical chemistry, and carcass characteristics of finishing lambs treated with recombinant ovine or bovine somatotropin. Journal of Nutrition, v.71, p.1453-1463, 1993.

MILES, L.E.M.; LIPSCHITZ, D.A.; BIEBER, C.P. et al. Measurement of serum ferritin by 2-site immunoradiometric assay. Analytical Biochemistry, v.61, p.209-224, 1974.

MORAIS, J.P.G. Rendimento de cortes e características das fibras musculares de bovinos superprecoces, com aplicação da somatotropina bovina recombinante. Botucatu: Universidade Estadual Paulista, 1999.51p. Tese(Doutorado em Ciências Biológicas) - Universidade Estadual Paulista, 1999.

MOREIRA, P.S.M. Desempenho produtivo em bezerros lactentes: efeitos da somatotropina bovina recombinante (rbST) sobre o tecido muscular e os níveis de hormônios tireoideanos (T3 e T4) e IGF-1. Botucatu: Universidade Estadual Paulista, 2002.118p. Tese (Doutorado em Ciências Biológicas) - Universidade Estadual Paulista, 2002.

MOSELEY, W.M.; PAULISSEN, J.B.; GOODWIN, M.C. et al. Recombinant bovine somatotropin improves growth performance in finishing beef steers. Journal of Animal Science, v.70, p.412-425, 1992.

MÜLLER, L. Normas para avaliação de carcaças e concurso de carcaças de novilhos. 2.ed. Santa Maria: Universidade Federal de Santa Maria, 1987. 31p.

NATIONAL RESEARCH COUNCIL - NRC. Nutrient requirements of beef cattle. 7.ed. Washington, D.C.: National Academy Press, 1996. 242p.

PAGANO, G.T.; LAZZARONI, C.; PAGANO, P.G. et al. A study on muscular hypertrophy in cattle: serum concentrations of IGF-I, cortisol, insulin and testosterone. Livestock Production Science, v.70, p.235-239, 2001.

PETERS, J.P. Consequences of accelerated gain and growth hormone administration for lipid metabolism in growing beef steers. Journal of Nutrition, v.116, p.2490-2503, 1986.

RAUSCH, M.I.; TRIPP, M.W.; GOVONI, K.E. et al. The influence of level of feeding on growth and serum insulin-like growth factor I and insulin-like growth factor-binding proteins in growing beef cattle supplemented with somatotropin. Journal of Animal Science, v.80, p.94-100, 2002. 
RENAVILLE, R.; DEVOLDER, A.; MASSART, S. Changes in the hypophisal-gonadal axis during the onset of puberty in young bulls. Journal of Reproduction Fertility, v.99, p.443-449, 1993.

RENAVILLE, R.; HAMMADI, M.; PORTETELLE, D. Role of the somatotropic axis in the mammalian metabolism. Domestic Animal Endocrinology, v.23, p.351-360, 2002.

ROCHE, J.F.; QUIRKE, J.F. Beef cattle production. London: Elsevier, 1992. 900p.

RUMSEY, T.S.; ELSASSER, T.H.; KAHL, S. et al. Effects of Synovex-S and recombinant bovine growth hormone (Somavubove) on growth responses of steers: I. Performance and composition of gain. Journal of Animal Science, v.74, p.2917-2928, 1996.

SANDLES, L.D.; PEEL, C.J. Growth and carcass composition of pre-pubertal dairy heifers treated with bovine growth hormone. Animal Production, v.44, p.21-27, 1987.

SCHWARZ, F.J.; SCHAMS, D.; ROPKE, R. et al. Effects of somatotropin treatment on growth performance, carcass traits, and the endocrine system in finishing beef heifers. Journal of Animal Science, v.71, p.2721-2731, 1993.

STATISTICAL ANALYSES SYSTEM - SAS. User's guide. 5.ed. Cary: 1997. 956p.

STICK, D.A.; DAVIS, M.E.; LOERCH, S.C. et al. Relationship between blood serum insulin-like growth factor I concentration and post weaning feed efficiency of crossbred cattle at three levels of dietary intake. Journal of Animal Science, v.76, p.498-505, 1998.

TRENKLE, A. Relation of hormonal variations to nutritional studies and metabolism in ruminants. Journal of Dairy Science, v.61, p.281-293, 1978.
TRIPP, M.W.; HOAGLAND, T.A.; DAHL, G.E. et al. Methionine and somatotropin supplementation in growing beef cattle. Journal of Animal Science, v.76, p.1197-1203, 1998.

VANN, R.C.; ALTHEN, T.G.; SMITH, W.K. et al. Recombinant bovine somatotropin (rbST) administration to creep-fed beef calves increase muscle mass but not affect satellite cell number or concentration of Myosin Light Chain-1f mRNA. Journal of Animal Science, v.76, p.1371-1379, 1998.

VERNON, R.G. Influence of somatotropin on metabolism. In: SEJRSEN, K.; VESTERGAARD, M.; NEIMANN-SORENSEN, A. (Eds.) Use of somatotropin in livestock production. London: Elsevier, 1989. p.31-50.

VESTERGAARD, M.; PURUP, S.; HENCKEL, P. et al. Effects of growth hormone and ovariectomy on performance, serum hormones, insulin-like growth factor-binding proteins, and muscle fiber properties of prepubertal friesian heifers. Journal of Animal Science, v.73, p.3574-3584, 1995.

WAGNER, J.F.; CAIN, T.; ANDERSON, D.B. et al. Effect of growth hormone $(\mathrm{GH})$ and estradiol $\left(\mathrm{E}^{2} \mathrm{~b}\right)$ alone and in combination on beef steer growth performance, carcass and plasma constituents. Journal of Animal Science, v.66, p.283 (Supl.1) (Abstr.), 1988.

WEEKS, T.E.C. Hormonal control of nutrient partition in growing ruminants. Journal of Reproduction Development, v.42, p.95-103, 1996.

Recebido em: 18/03/04

Aceito em: 08/06/05 